\title{
A New Class of Near Infrared Electrochromic Oxamide-Based Dinuclear Ruthenium Complexes
}

Majid F. Rastegar, Erin K. Todd, Hongding Tang, Zhi Yuan Wang* 


\section{General procedure for the synthesis of OXA-Ru complexes $2 \mathrm{a}-\mathbf{j}$, using $2 \mathrm{a}$ as a typical example}

In a $250 \mathrm{~mL}$ round-bottomed flask, $34.84 \mathrm{mg}(0.3 \mathrm{mmol})$ of $\mathrm{N}, \mathrm{N}$ '-dimethyl oxamide, $0.3122 \mathrm{~g}$ of $\mathrm{Ru}(\mathrm{bpy})_{2} \mathrm{Cl}_{2}(0.60 \mathrm{mmol})$ and $24.0 \mathrm{mg}(0.60 \mathrm{mmol})$ of sodium hydroxide were charged, followed by addition of $100 \mathrm{~mL}$ of aqueous ethanol (85\%). The mixture was heated to reflux under the nitrogen atmosphere for 24 hours. After cooling to room temperature, a solution of ammonium hexafluorophosphate $(1.6137 \mathrm{~g})$ dissolved in 60 $\mathrm{mL}$ of distilled water was added. After stirring for two more hours, the brown precipitates were collected by filtration and dried in air. The crude product purified by chromotography using neutral alumina gel and a mixture of acetonitrile and toluene $(1: 1$ $\mathrm{v} / \mathrm{v}$ ) as eluant. After removal of solvent, the solid residue was dissolved in a minimum amount of acetone and the acetone solution was slowly added into $100 \mathrm{~mL}$ of diethyl ether with stirring. The resulting precipitates were collected and washed with diethyl ether and dried in air and then in a vacuum oven at $45^{\circ} \mathrm{C}$ overnight. Complex 2a was obtained in $80 \%$ yield $(0.297 \mathrm{~g})$. ESI-MS showed $\mathrm{m} / \mathrm{z} 1086$ corresponding to $\left\{\left(\text { complex }{ }^{2+}\right) \mathrm{PF}_{6}^{-}\right\}^{+}$species. 
$2 \mathrm{a}$
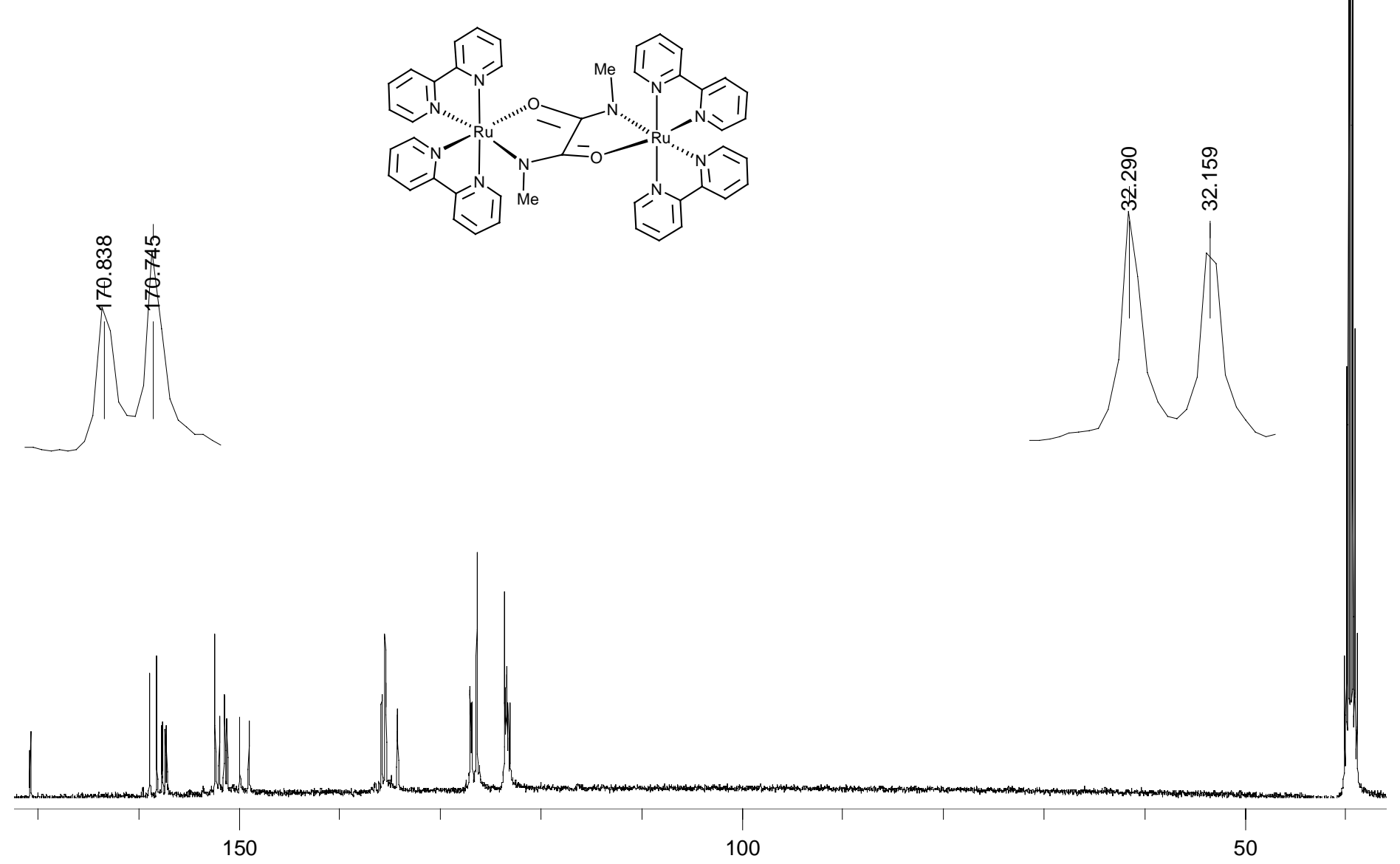

ppm (f1) 


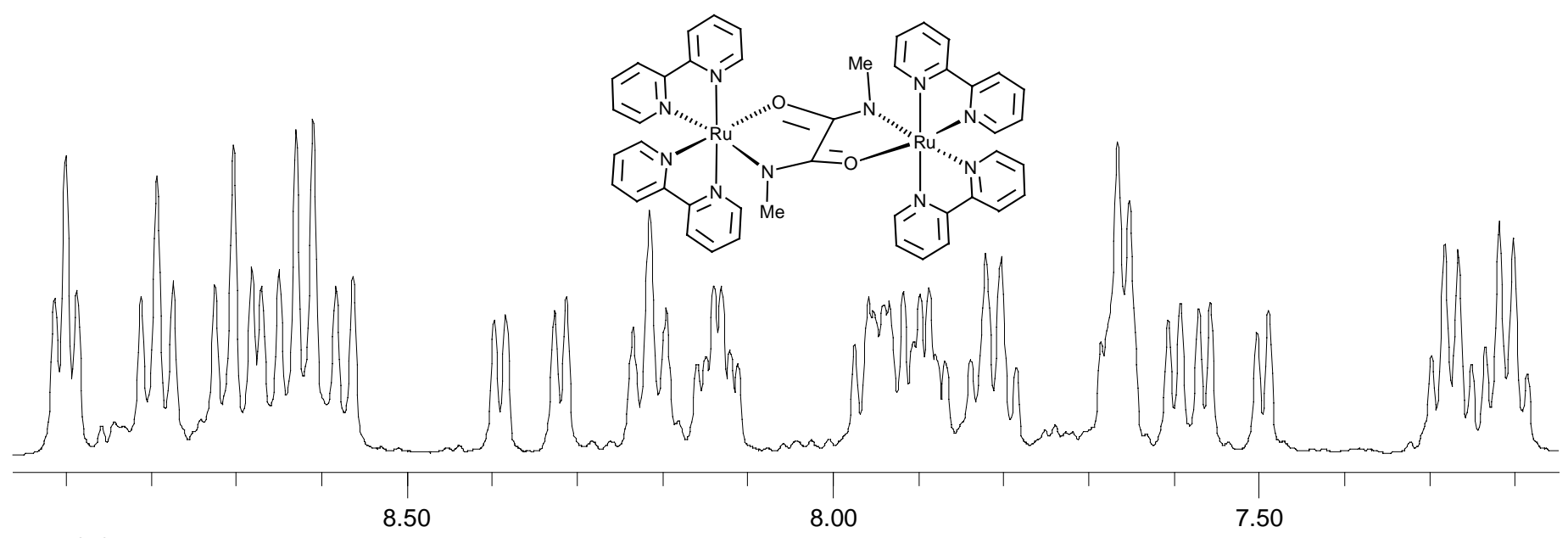

ppm (f1)

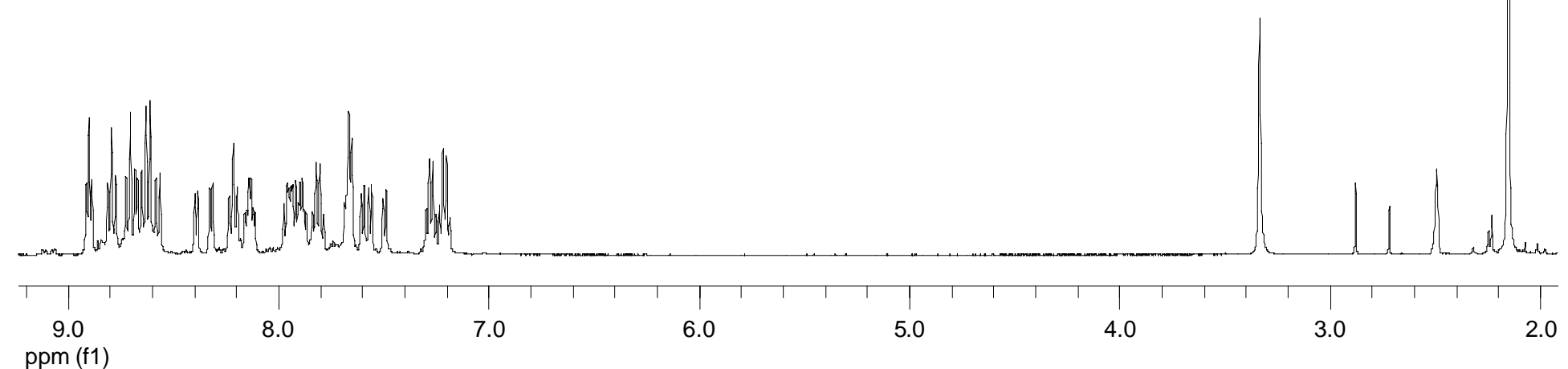


$2 b$

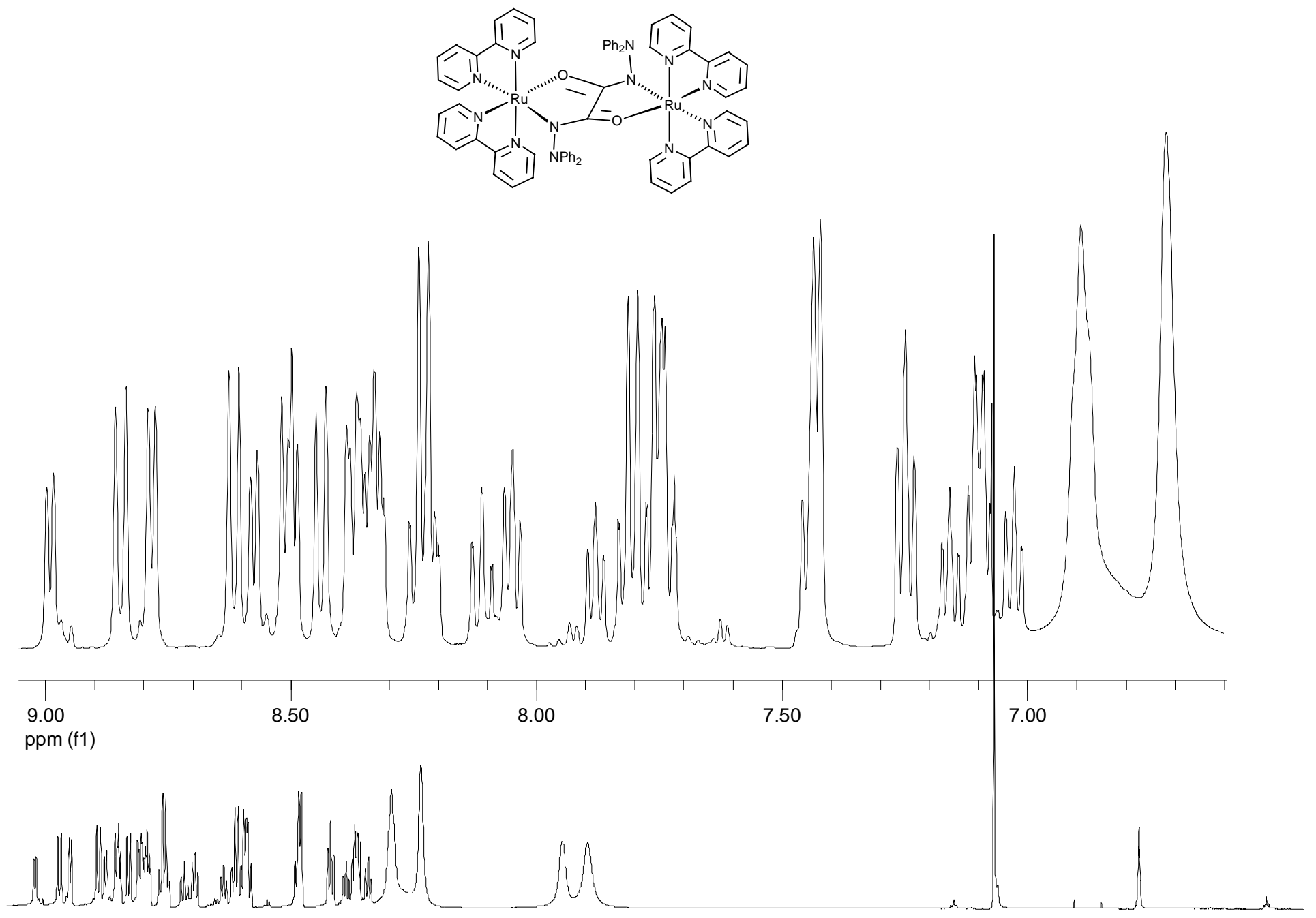

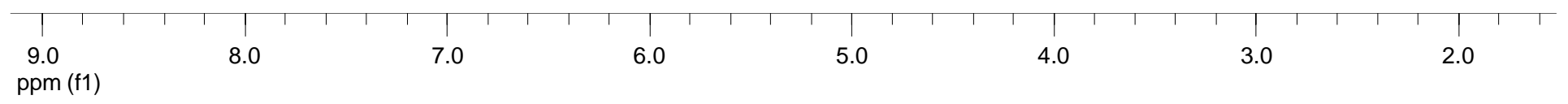


$2 b$
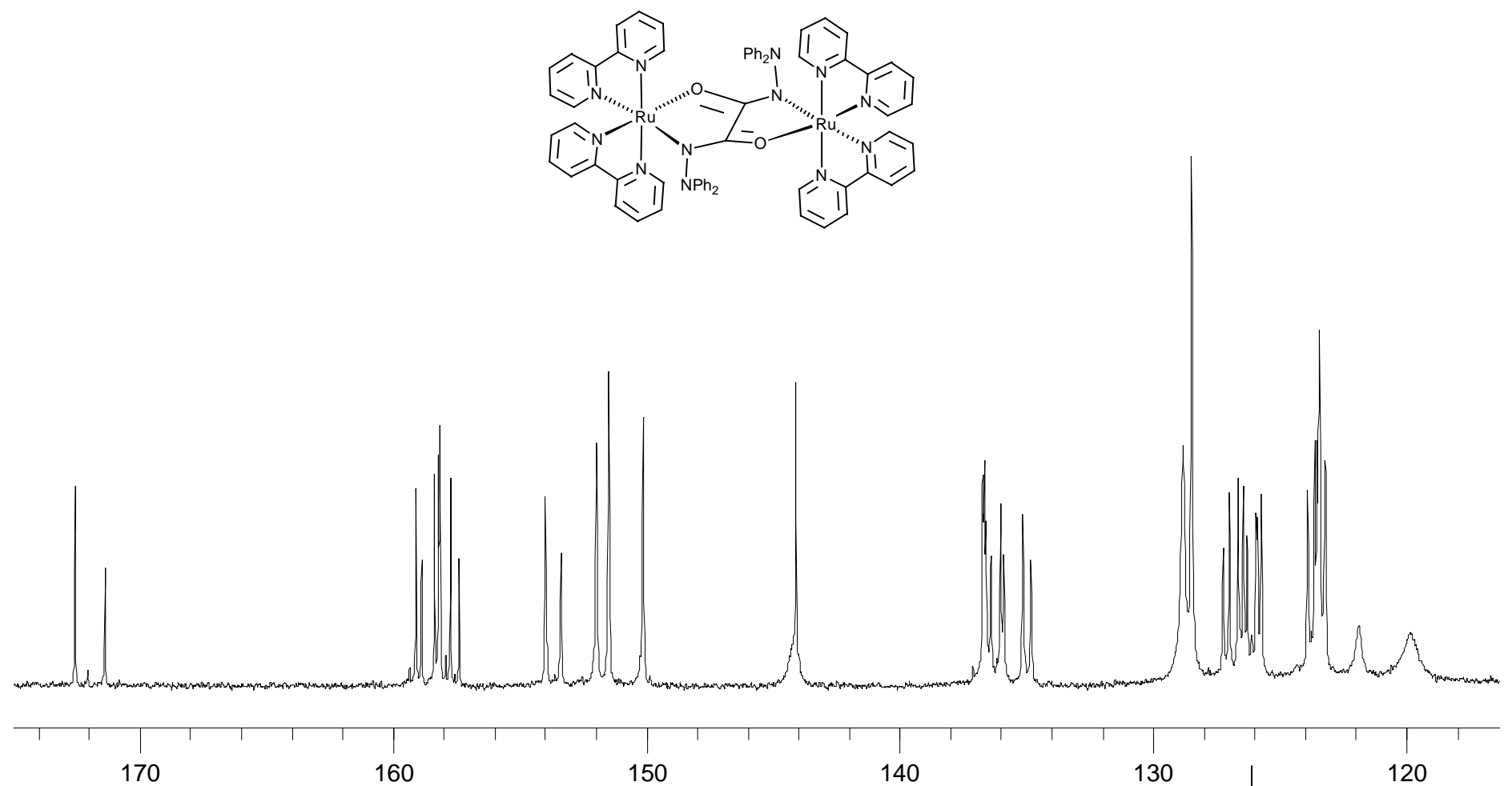

ppm (f1)

60

140

130

20

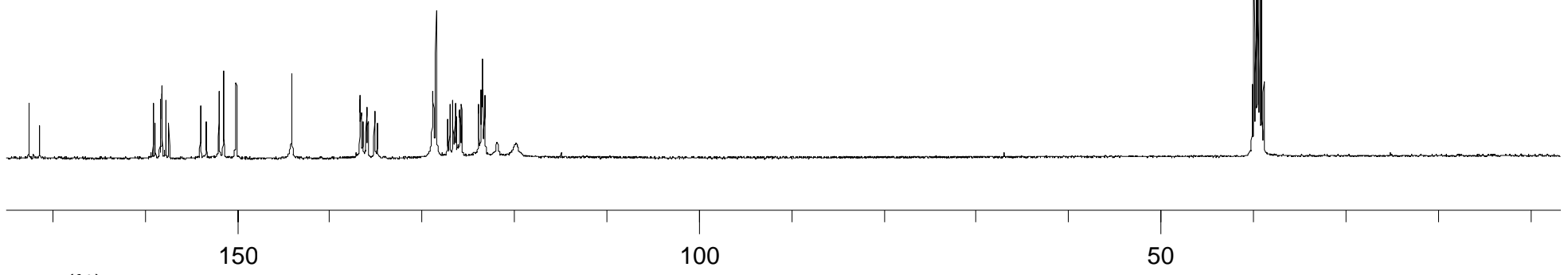

ppm (f1) 
$2 c$
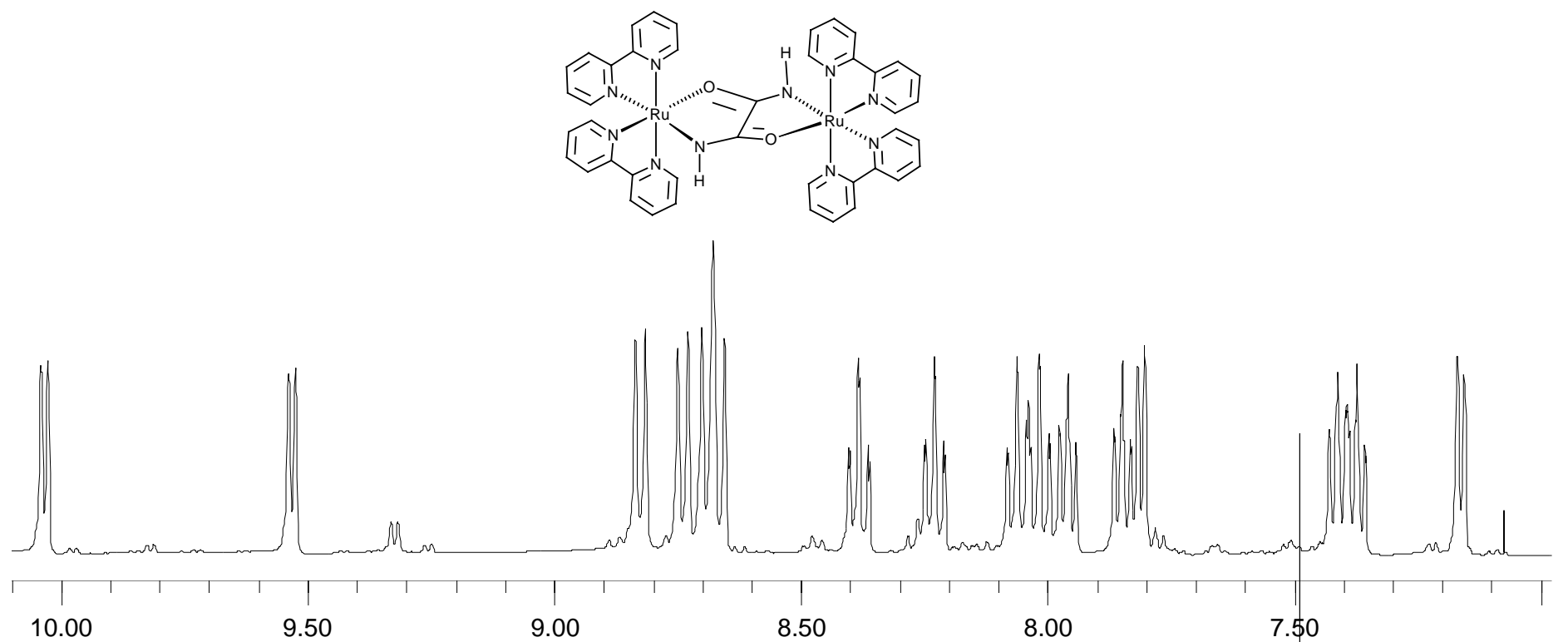

ppm (f1)
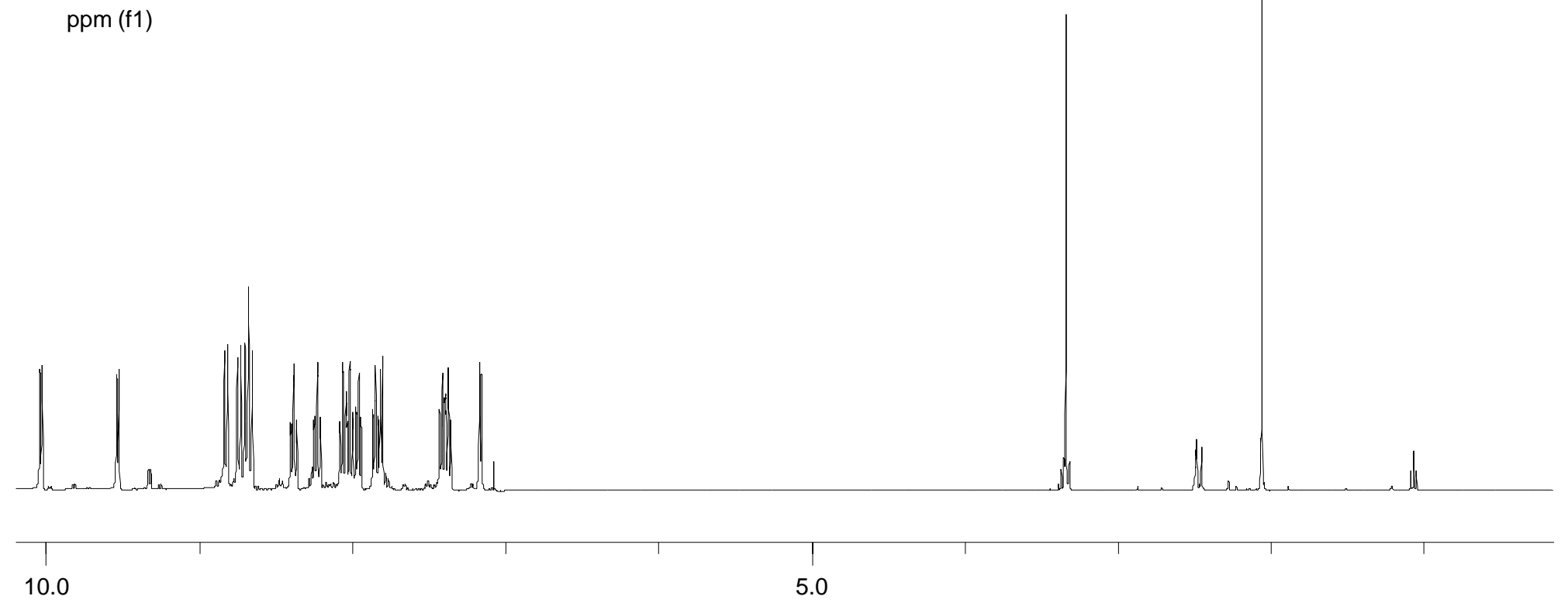

ppm (f1)

5.0 
2c
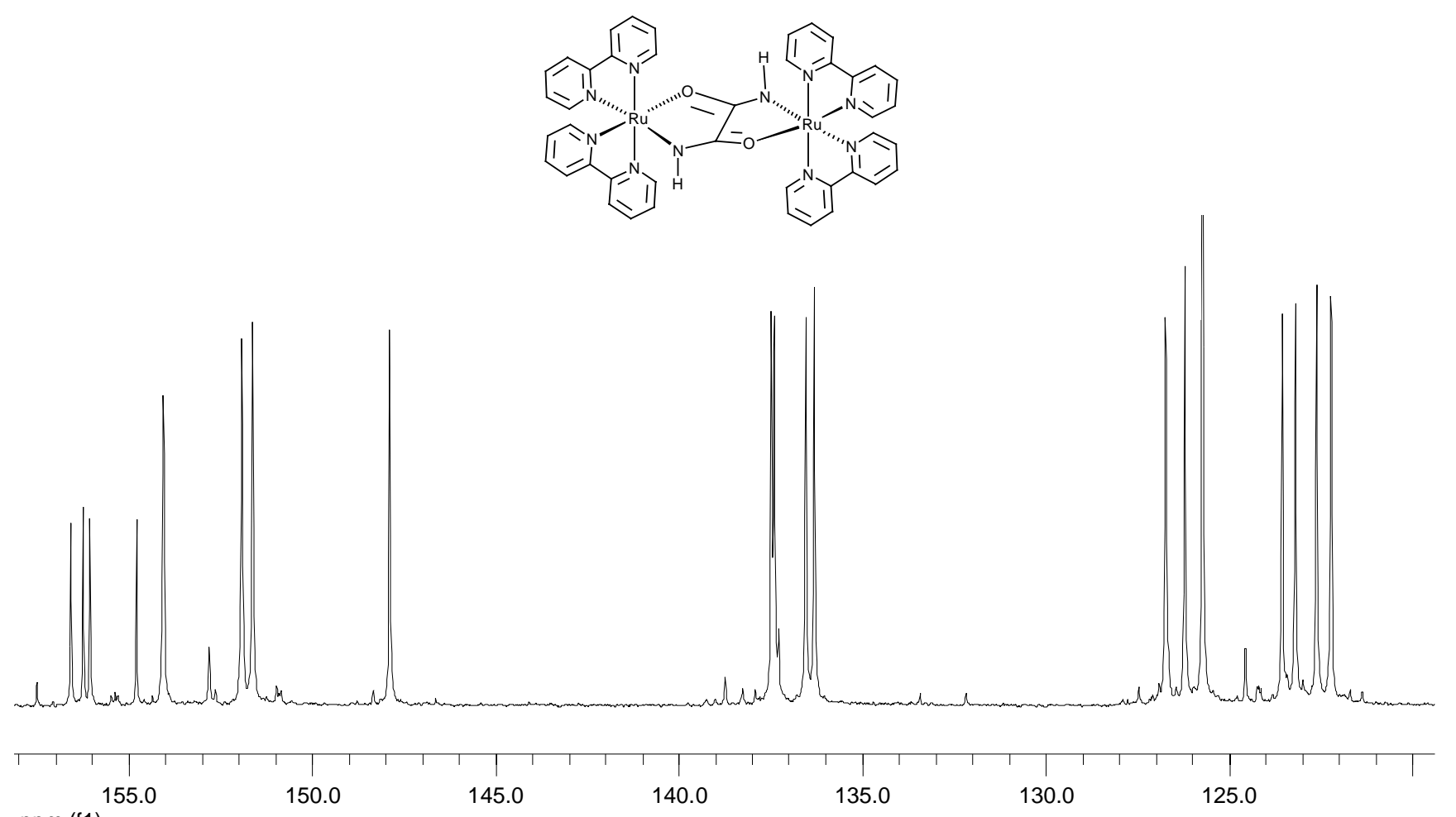
ppm (f1)

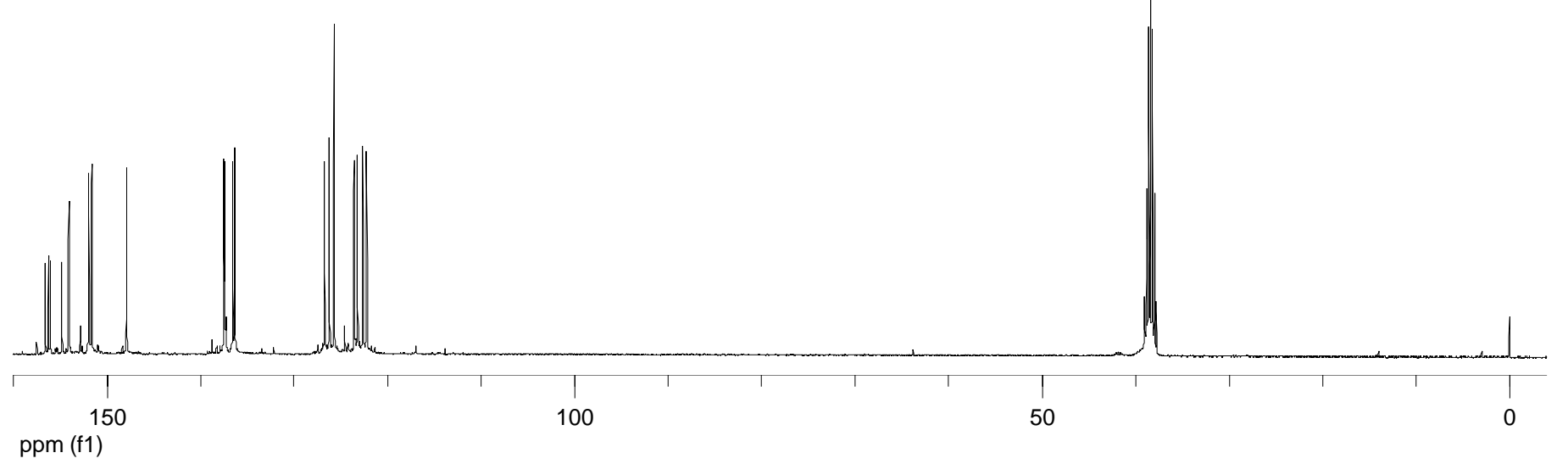




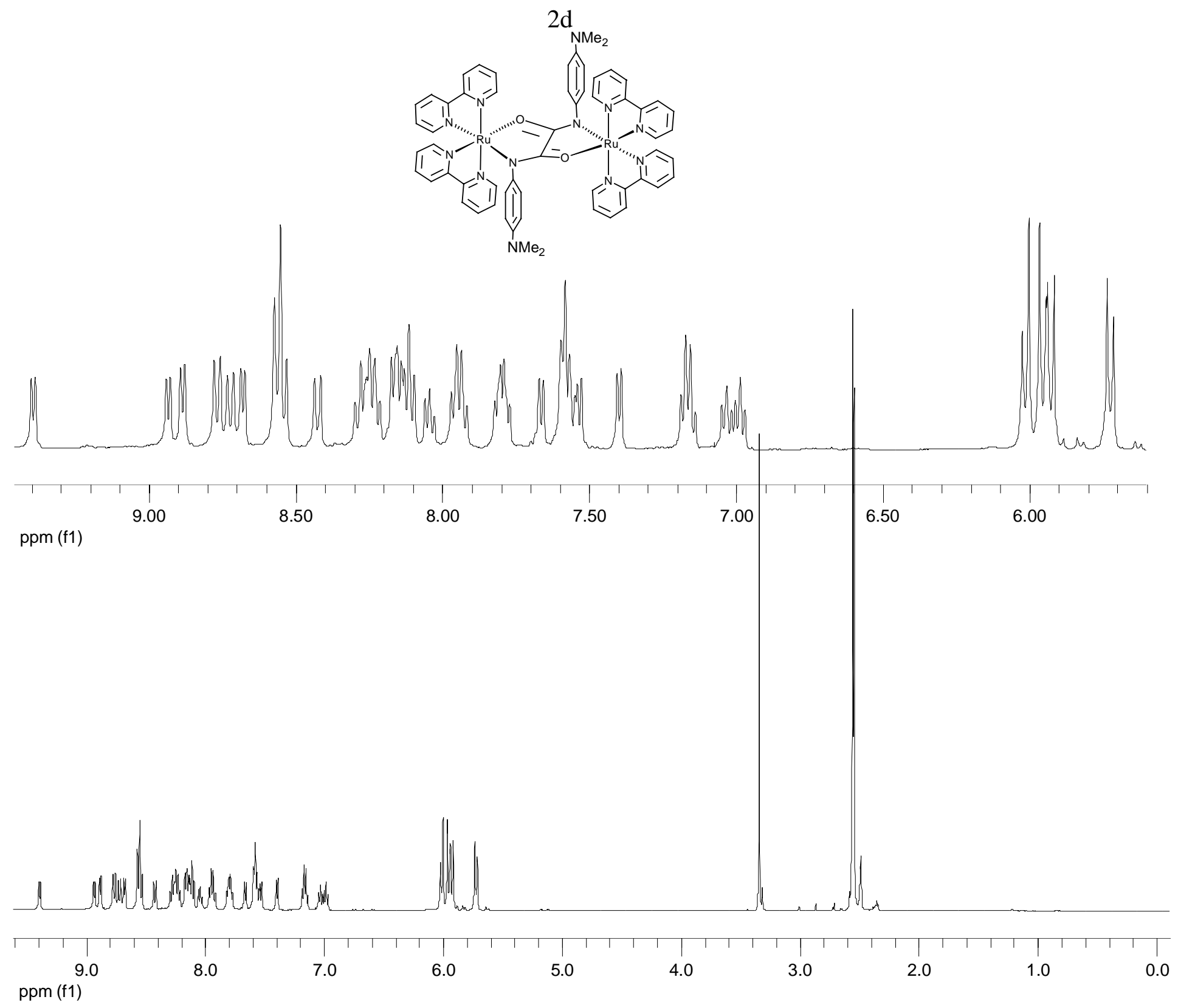




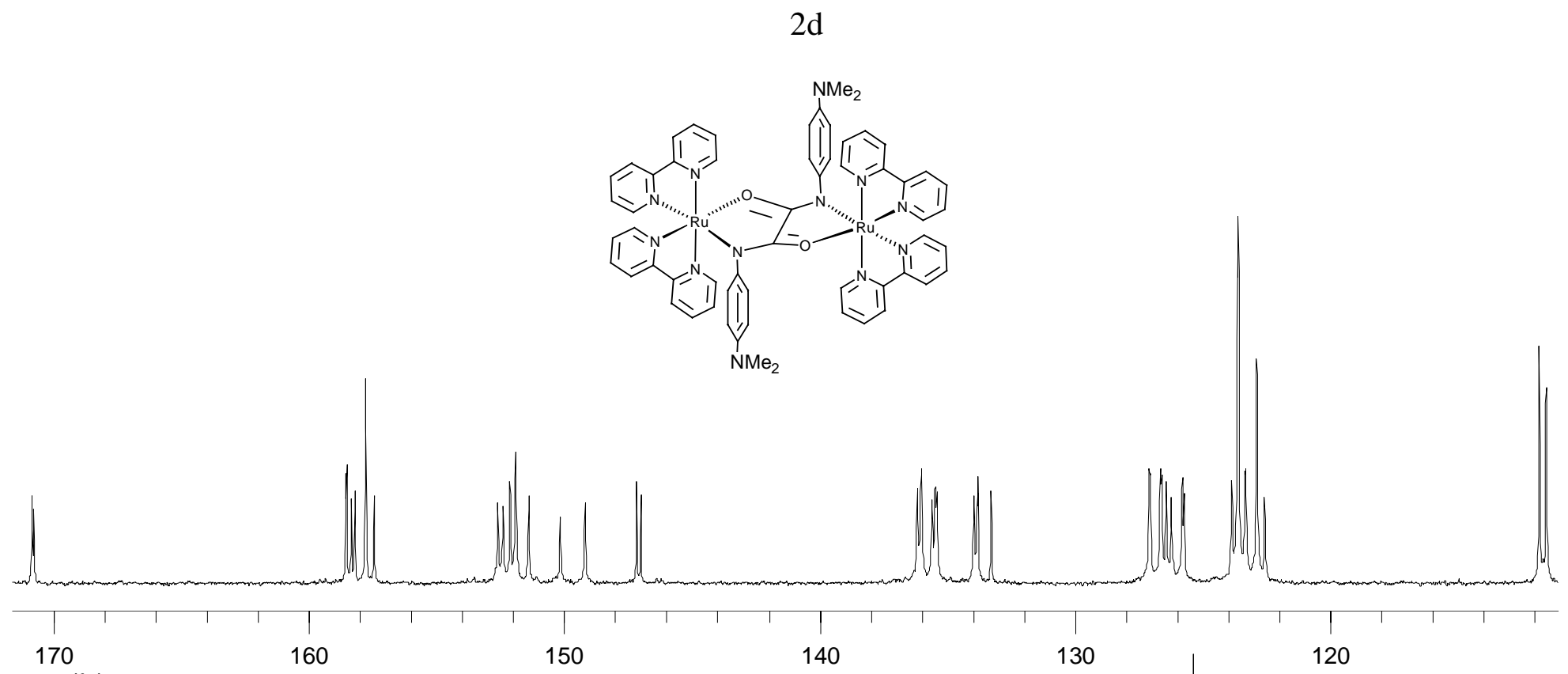

ppm (f1)

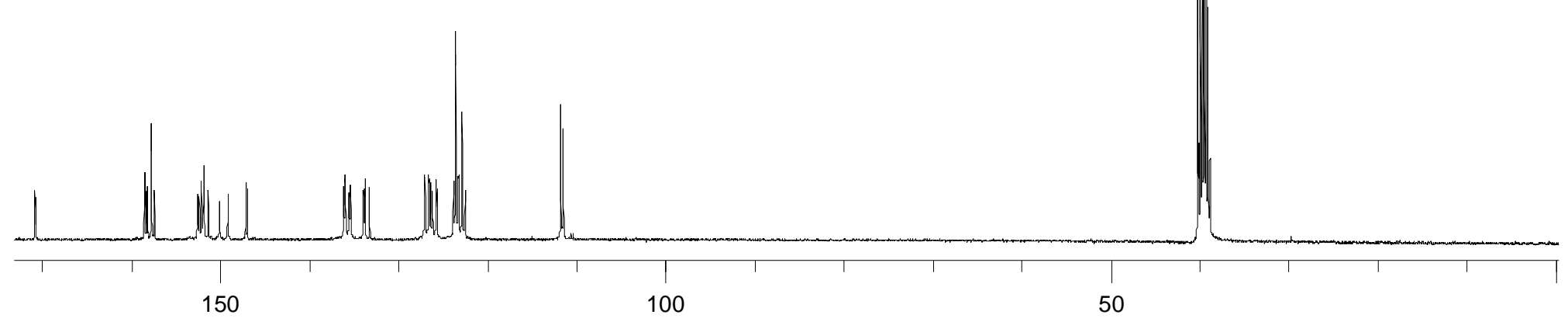

ppm (f1) 

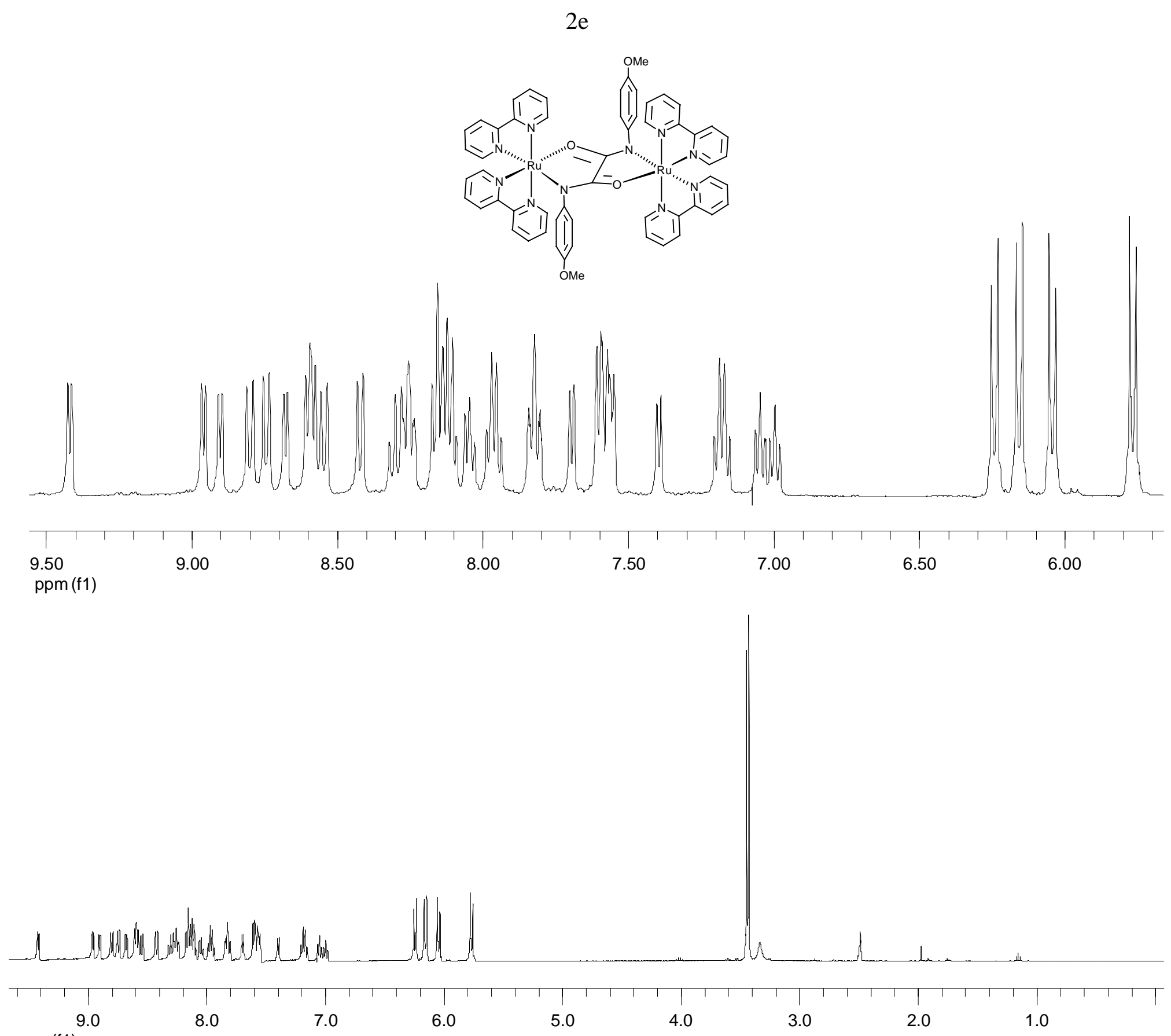
ppm (f1) 


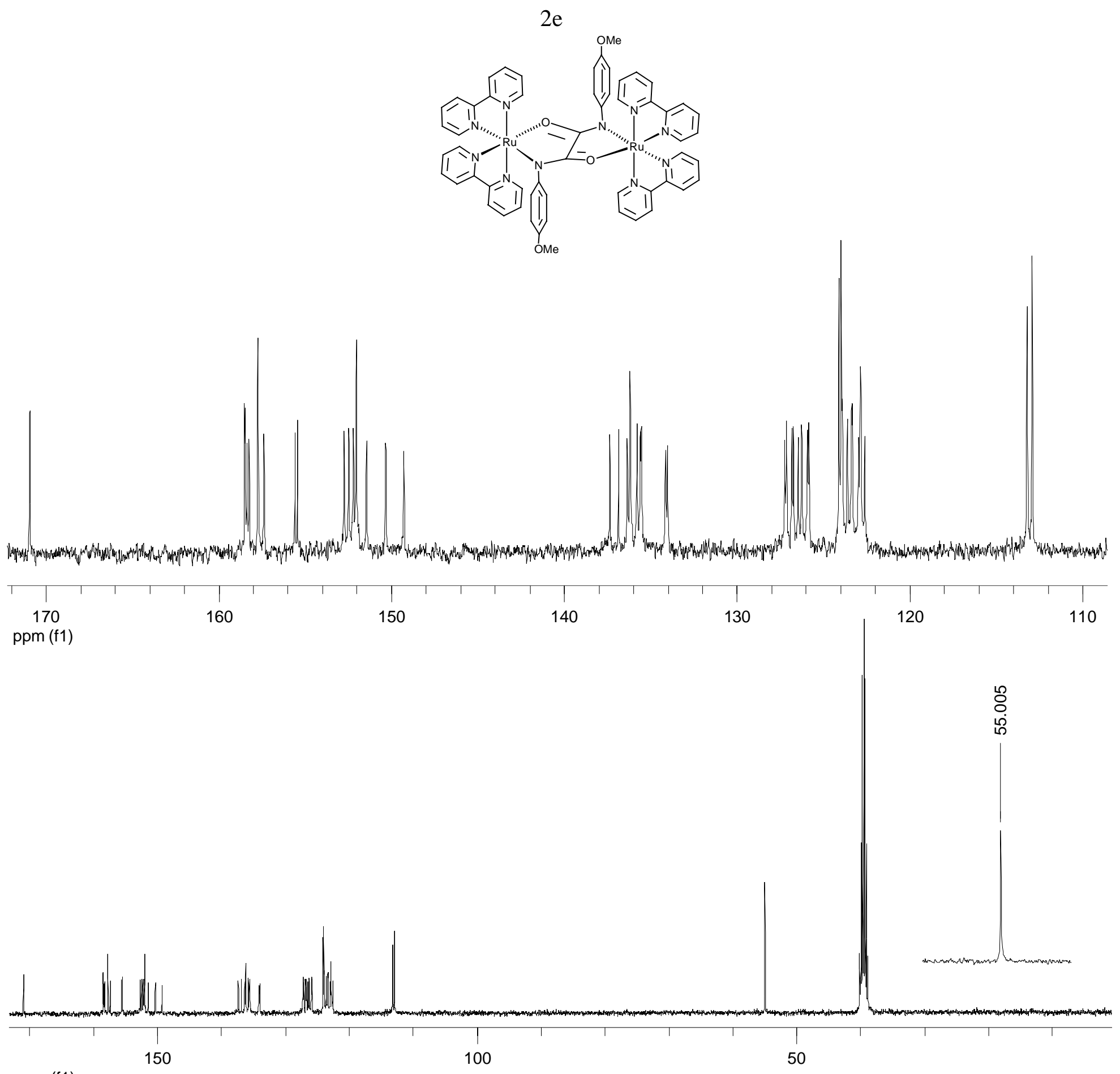

ppm (f1) 


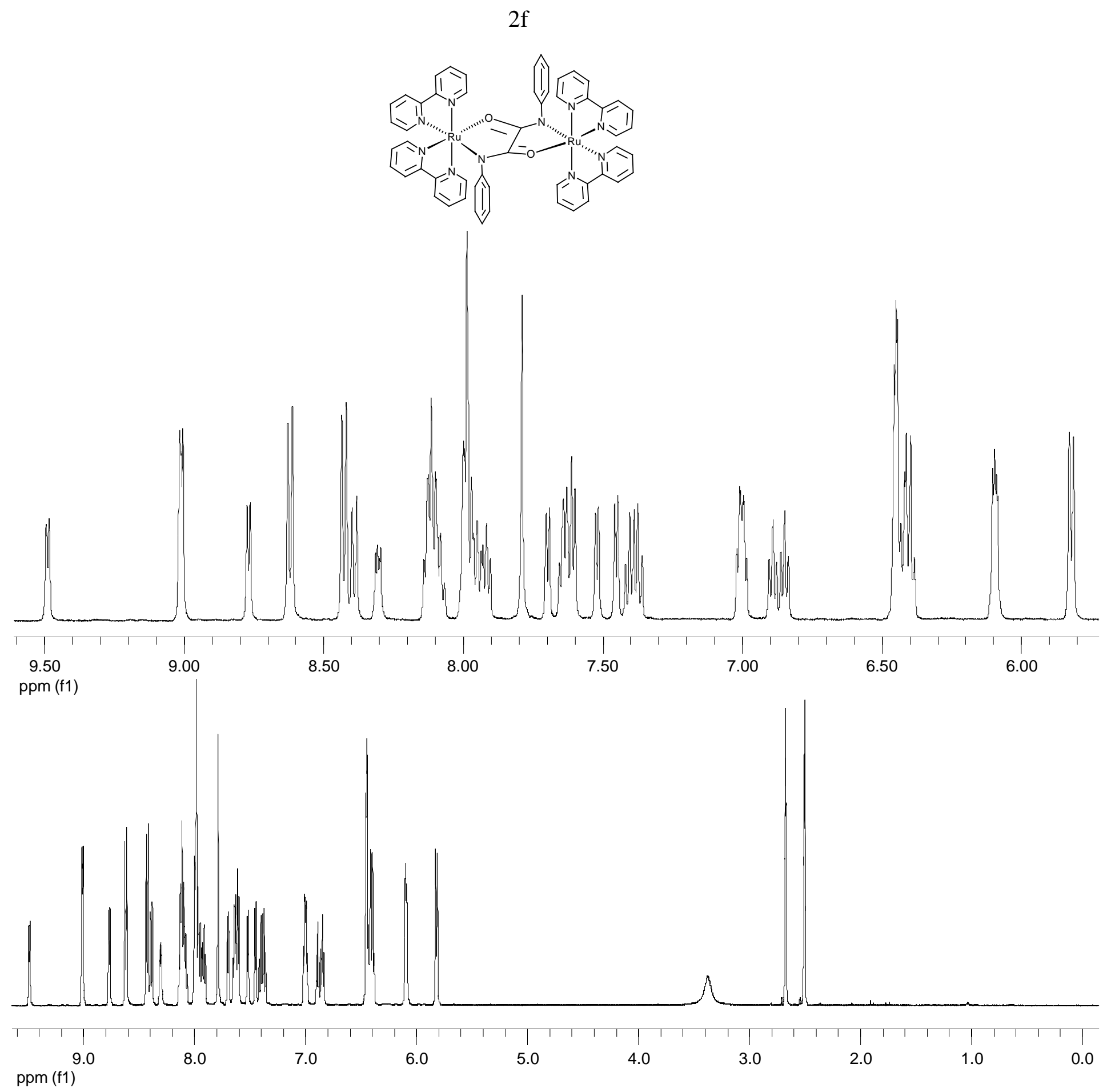



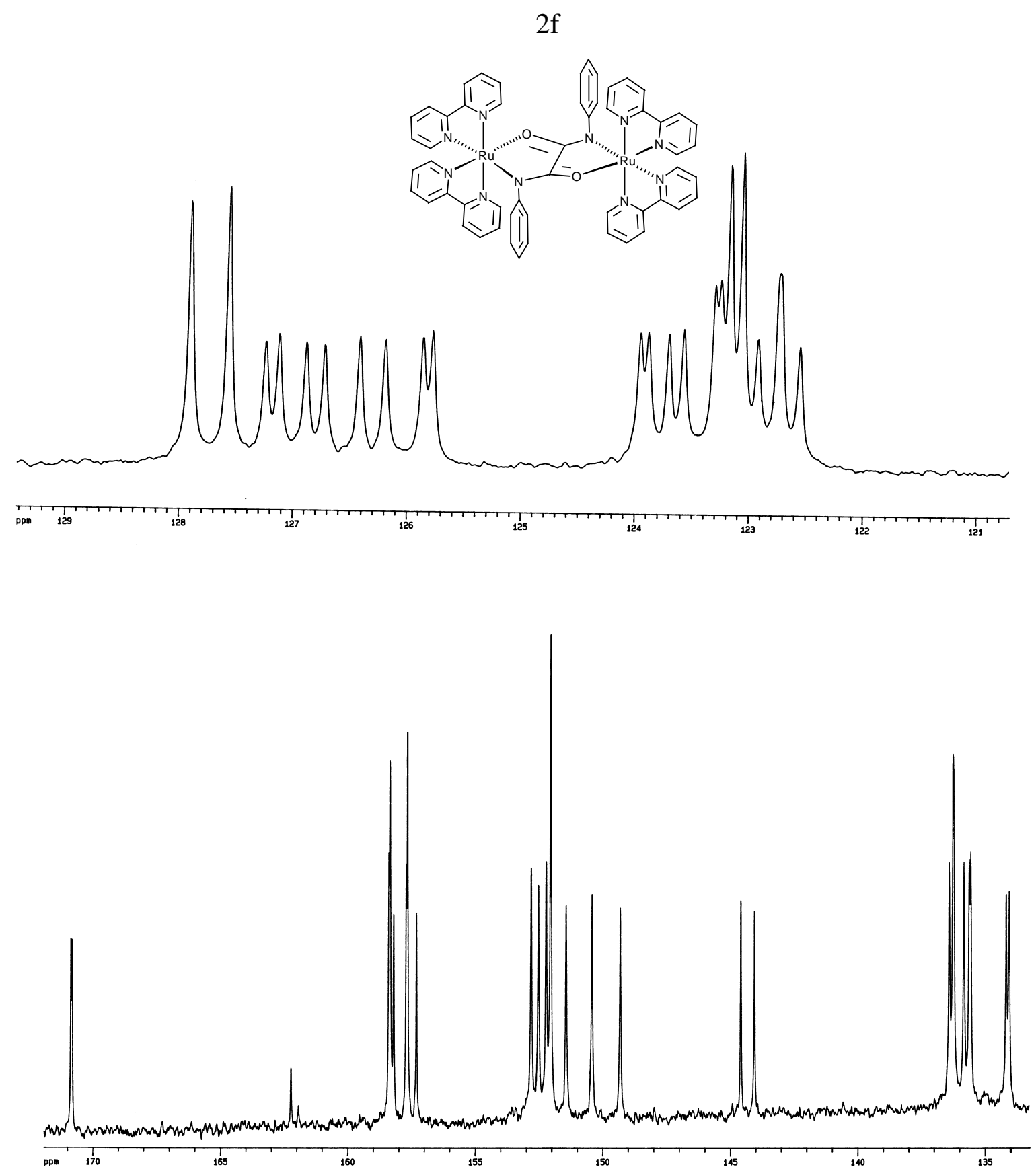


\section{$2 \mathrm{~g}$}
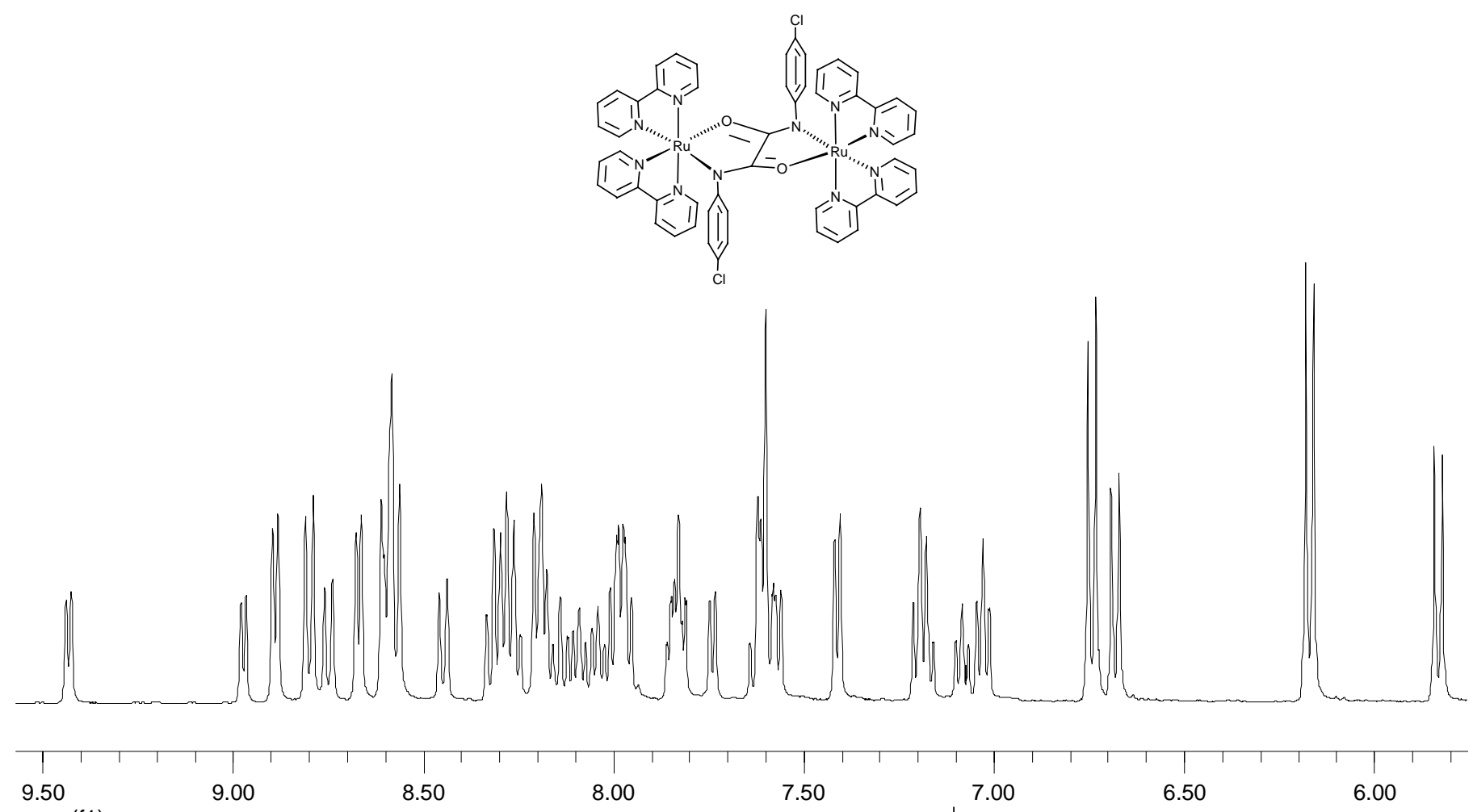

ppm (f1)
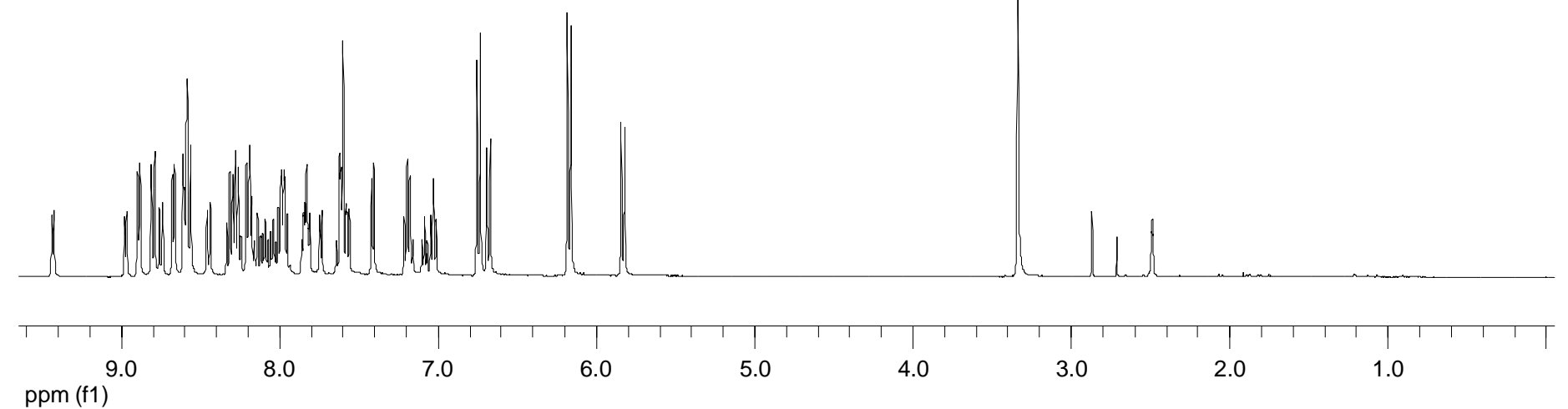


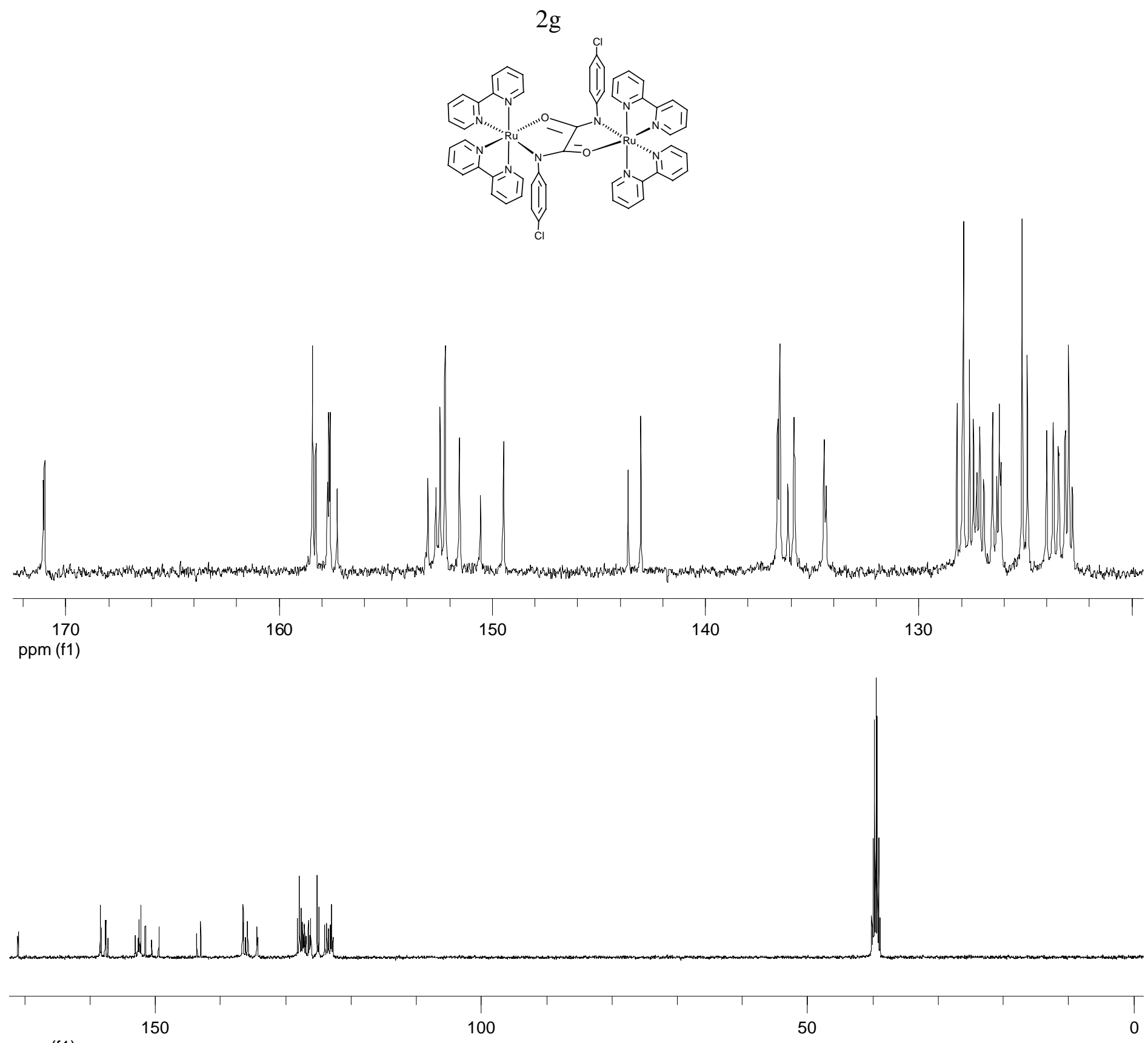

ppm (f1) 
$2 \mathrm{~h}$

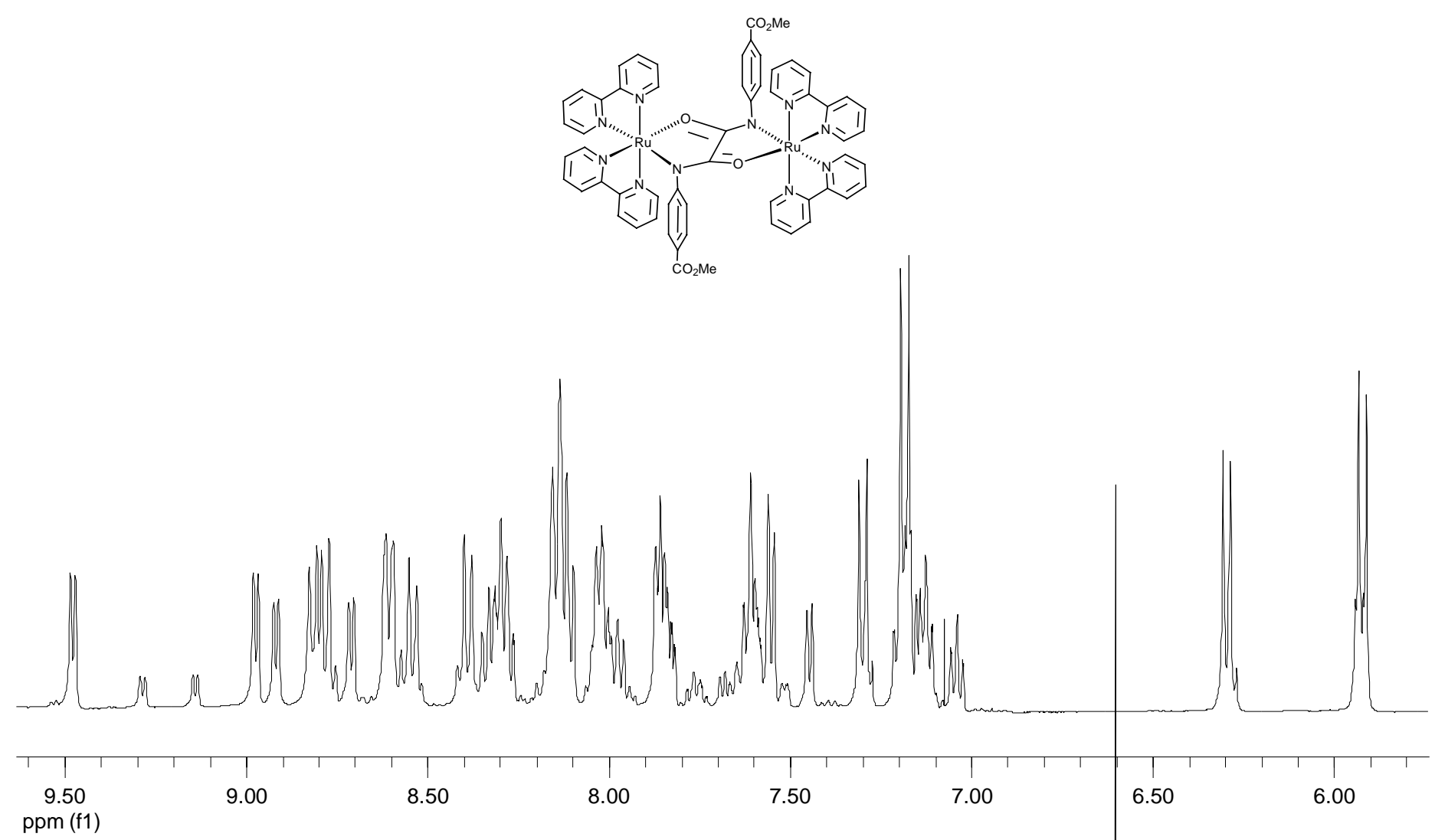

ppm (f1)

8.50 


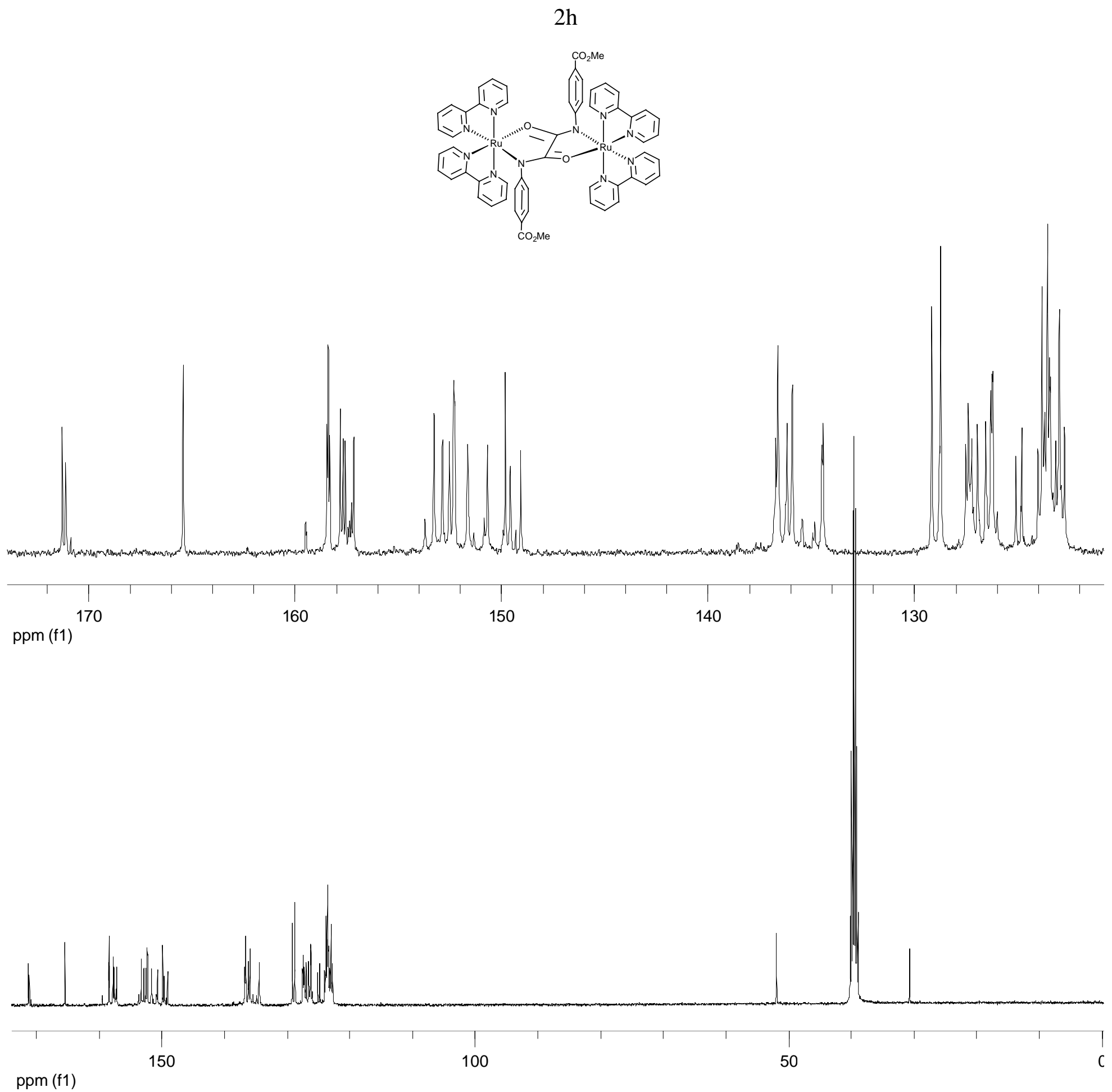



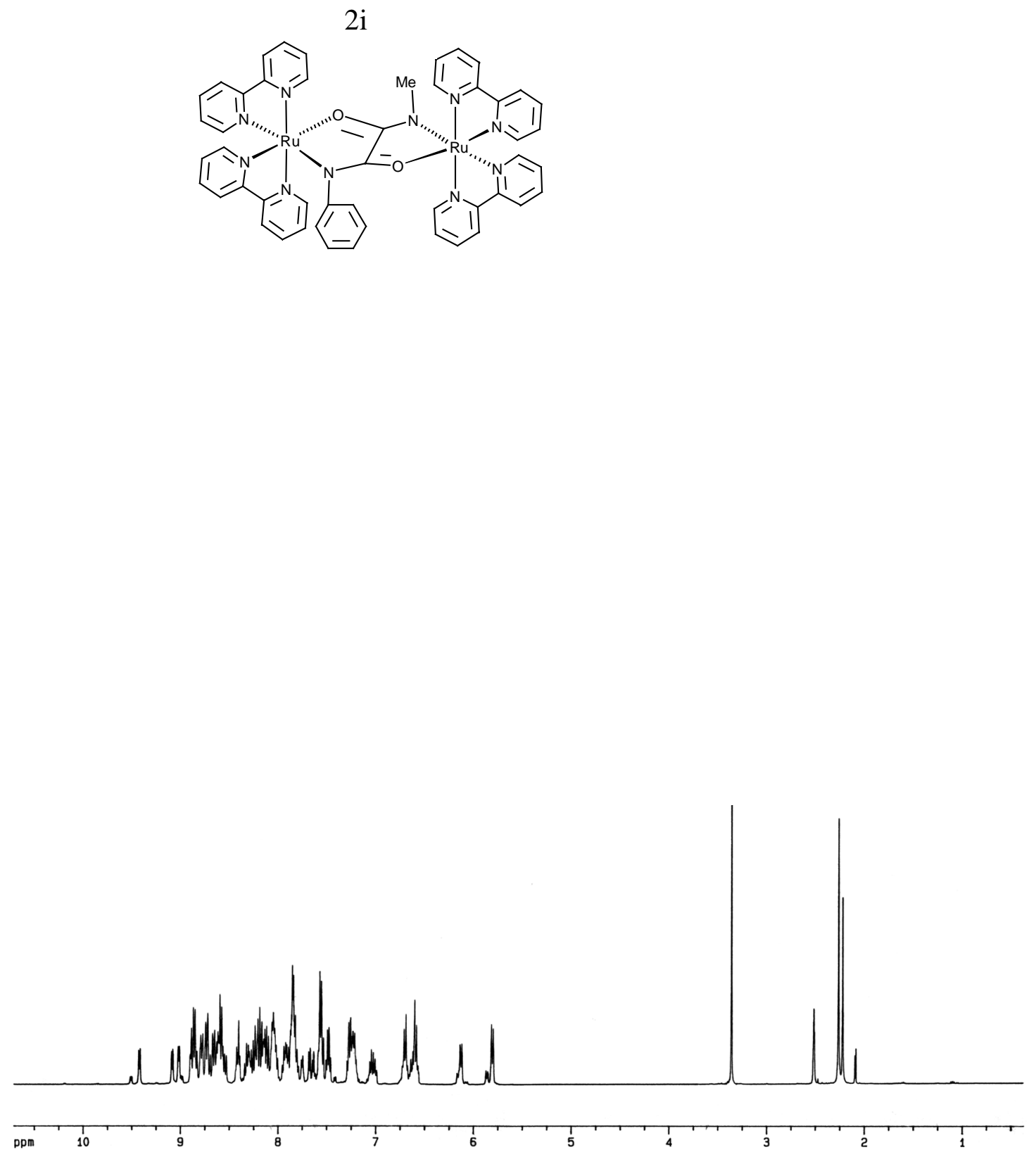

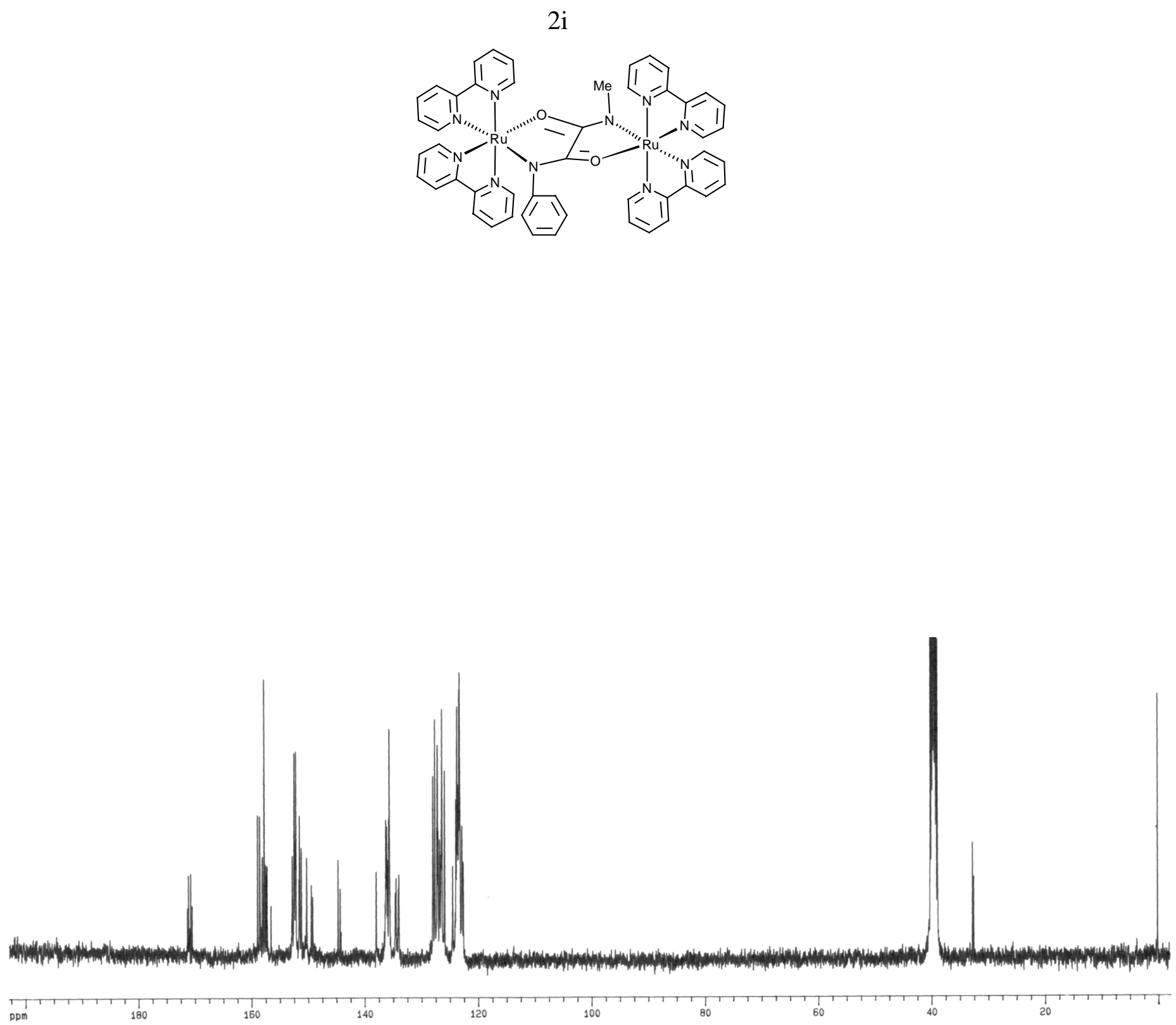


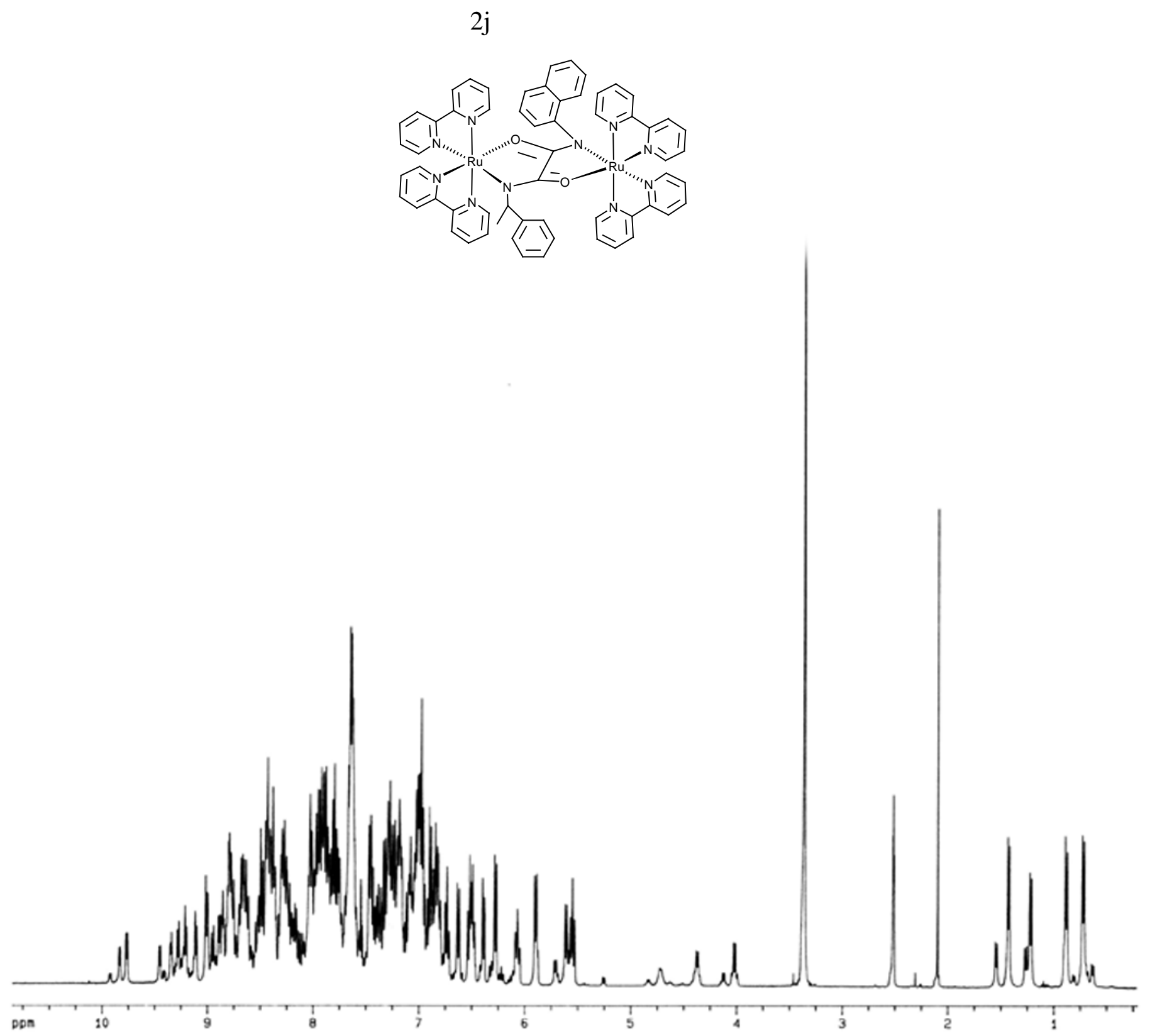


22

$2 \mathrm{j}$
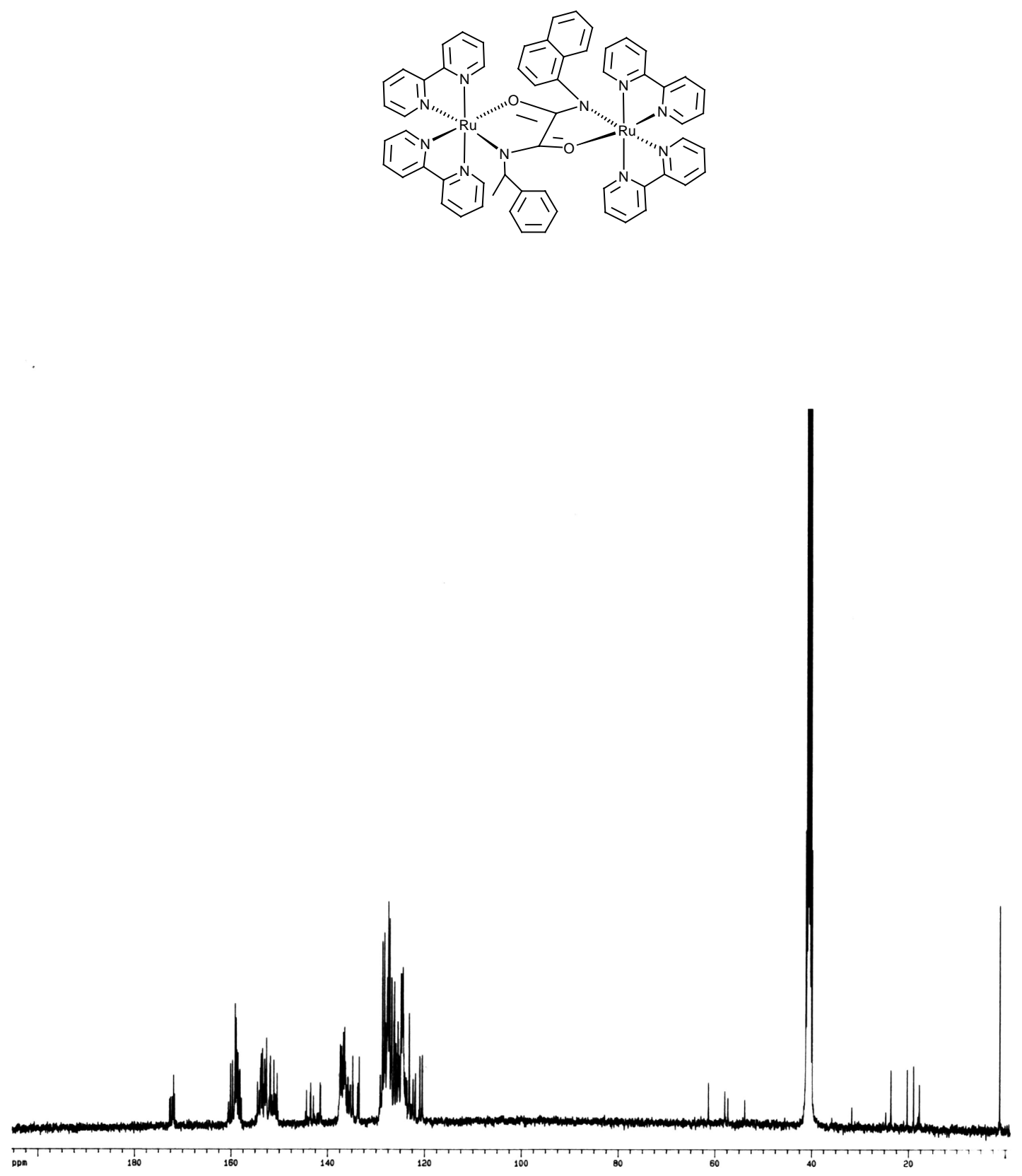